\title{
Biosensor based on tyrosinase immobilized on a single-walled carbon nanotube-modified glassy carbon electrode for detection of epinephrine
}

This article was published in the following Dove Press journal:

International Journal of Nanomedicine

II November 2013

Number of times this article has been viewed

\author{
Irina Mirela Apetrei' \\ Constantin Apetrei ${ }^{2}$ \\ 'Department of Pharmaceutical \\ Sciences, Faculty of Medicine and \\ Pharmacy, ${ }^{2}$ Department of Chemistry, \\ Physics and Environment, Faculty of \\ Sciences and Environment, Dunarea \\ de Jos University of Galati, Romania
}

Correspondence: Constantin Apetrei Department of Chemistry, Physics and Environment, Faculty of Sciences and Environment, Dunarea de Jos University of Galati, 47 Domneasca Street, 800008 Galati, Romania Tel +400236460328

Fax +40023646 I353

Email apetreic@ugal.ro

\begin{abstract}
A biosensor comprising tyrosinase immobilized on a single-walled carbon nanotube-modified glassy carbon electrode has been developed. The sensitive element, ie, tyrosinase, was immobilized using a drop-and-dry method followed by cross-linking. Tyrosinase maintained high bioactivity on this nanomaterial, catalyzing the oxidation of epinephrine to epinephrine-quinone, which was electrochemically reduced $(-0.07 \mathrm{~V}$ versus $\mathrm{Ag} / \mathrm{AgCl})$ on the biosensor surface. Under optimum conditions, the biosensor showed a linear response in the range of $10-110 \mu \mathrm{M}$. The limit of detection was calculated to be $2.54 \mu \mathrm{M}$ with a correlation coefficient of 0.977 . The repeatability, expressed as the relative standard deviation for five consecutive determinations of $10^{-5} \mathrm{M}$ epinephrine solution was $3.4 \%$. A good correlation was obtained between results obtained by the biosensor and those obtained by ultraviolet spectrophotometric methods
\end{abstract}

Keywords: amperometry, single-walled carbon nanotubes, spectrophotometry, catecholamine, pharmaceutical formula

\section{Introduction}

Epinephrine belongs to the catecholamine group and has an important role as a neurotransmitter and hormone. It is biosynthesized in the adrenal medulla and sympathetic nerve terminals, and is secreted by the adrenal glands. ${ }^{1,2}$ Epinephrine is used in medicine to treat heart attacks and bronchial asthma, and in cardiac surgery. ${ }^{3,4}$ Therefore, determination of epinephrine in biological fluids is of great importance in medical diagnosis, in particular for patients suffering from Parkinson's disease. For this reason, there is a need for quantitative determination of epinephrine in biological fluids and pharmaceutical formulations. $^{2}$

Several methods have been used to determine epinephrine, including spectrophotometry, ${ }^{5,6}$ fluorimetry, ${ }^{7}$ liquid chromatography, ${ }^{8}$ capillary electrophoresis, ${ }^{9}$ and piezoelectric detection. ${ }^{10}$ However, these methods tend to be expensive, complicated, or need extraction and derivatization. The main advantages of biosensor technology in comparison with traditional analytical methods are fast detection (minutes) and response (seconds), high sensitivity (typically lower than $\mu \mathrm{M}$ ), good selectivity, and easy preparation and assay methods. Additionally, most biosensors are reusable and can be assayed at low cost.

Electrochemical biosensors based on immobilization of tyrosinase on nanomaterials provide an alternative to other analytical techniques for catecholamine determination. ${ }^{11,12}$ The electroanalytic technique based on biosensors is remarkable because of its simplicity, low cost, high sensitivity, and potential for miniaturization. ${ }^{12}$ Numerous biosensors 
have been developed using tyrosinase immobilized on different electrode supports. Different types of biosensors can be found in the literature, including carbon paste biosensors, ${ }^{13}$ conducting polymer-modified electrodes, ${ }^{12,14}$ biosensors based on silica sol-gel composite films, ${ }^{15}$ Langmuir-Blodgett thin films, ${ }^{16,17}$ and layer-by-layer films. ${ }^{18}$

Use of a biocompatible matrix for tyrosine immobilization is essential for maintaining the functionality of the enzyme while providing accessibility to the target analyte. The noncovalent approach is considered to be a more promising method, because there is less distortion of the conformational structure of the immobilized enzyme. ${ }^{19}$ Carbon nanotubes, in addition to having very interesting mechanical, electrical, and thermal properties, provide a large surface area for higher enzyme loading and a biocompatible environment that helps enzymes to preserve their biocatalytic properties. ${ }^{20}$ Compared with multiwalled carbon nanotubes, single-walled carbon nanotubes (SWCNTs) have a well defined system in terms of electronic properties. For enzyme immobilization, multiwalled carbon nanotubes are desirable because of their easy dispersibility and low cost, but SWCNTs are attractive because of their larger surface area for enzyme interaction. SWCNTs are usually arranged in a regular pattern and are in contact with each other. Moreover, SWCNTs can be seen as a bridge connecting electrodes with various kinds of biomolecules, while they are aligned normally to the electrode surface by self-assembly and act as nanoelectrodes. ${ }^{21}$

In this paper, an innovative biosensor is introduced for determination of epinephrine in pharmaceutical samples and offers the advantages of high sensitivity, low cost, and simple fabrication. The response dependence and amperometric characteristics, including kinetics, calibration curve, and limit of detection of the prepared biosensor were investigated in the detection of epinephrine. The results obtained for the proposed biosensor were compared with those using the standard method of ultraviolet spectrophotometry.

\section{Materials and methods}

\section{Apparatus}

Amperometric measurements were performed using an SP-150 potentiostat/galvanostat (Biologic Science Instruments, Claix, France) and EC-Lab Express software (Biologic Science Instruments). $\mathrm{Ag} / \mathrm{AgCl} 3 \mathrm{M} \mathrm{KCl}$ was used as the reference electrode and a platinum wire was used as the auxiliary electrode. The working electrode was the biosensor. An Elmasonic S10H ultrasonic bath (Elma Hans Schmidbauer $\mathrm{GmbH}$ and $\mathrm{Co}$, KG, Singen, Germany) was used to dissolve and homogenize the solutions. For $\mathrm{pH}$ measurements, an
Inolab pH 7310 (WTW Wissenschaftlich-Technische Werkstätten GmbH, Weilheim in Oberbayern, Germany) was used. An ultraviolet-visible spectrophotometer (model UVD-2950, Labomed, Inc., Los Angeles, CA, USA) with a quartz cell (optical path $1 \mathrm{~cm}$ and total volume $4 \mathrm{~mL}$ ) was used for measurements following an official spectrophotometric method (X Romanian Pharmacopoeia).

\section{Reagents and solutions}

All solutions were prepared using ultrapure water (Milli-Q Simplicity ${ }^{\circledR}$ Water Purification System, EMD Millipore Corporation, Billerica, MA, USA) with resistivity of $18.3 \mathrm{M} \Omega$. Epinephrine [adrenaline or 1-(3,4-dihydroxyphenyl)-2-methyloaminoethanol], sodium monohydrogen phosphate, and potassium dihydrogen phosphate were purchased from Sigma-Aldrich (St Louis, MO, USA). Methanol was sourced from Merck \& Co., Inc. (Whitehouse Station, NJ, USA). The SWCNTs were obtained from Nanoledge Inc (Boucherville, Quebec, Canada). These have a purity of more than $95 \%$ and were used without any chemical treatment. A glassy carbon electrode (GCE) was purchased from Radiometer Analytical SAS (Lyon, France). Tyrosinase (from the EC 232-653-4 mushroom, activity $5,370 \mathrm{U} / \mathrm{mg}$ of solid) was purchased from Sigma-Aldrich. A $50 \mu \mathrm{g} / \mu \mathrm{L}$ solution of tyrosinase in phosphate-buffered solution (PBS, 0.01 M, pH 7.0) was used to immobilize the enzyme. Sodium chloride and sodium metabisulfite (Sigma-Aldrich), urea (Merck), L-(+)-tartaric acid (Sigma-Aldrich), hydrochloric acid (S.C. Chemical Company S.A., Iasi, Romania), glycine (Sigma-Aldrich), and D(+)-glucose (Acros Organics, Fair Lawn, NJ, USA) were used for the interference studies.

\section{Construction of biosensor}

The GCE surface was polished with alumina paste, washed with ultrapure water, and rinsed in methanol. The active part of the electrode was a $4 \mathrm{~mm}$ diameter disk. The other parts of the GCE were covered with isolating epoxy resin. After cleaning, the GCE surface was coated with $10 \mu \mathrm{L}$ of SWCNT suspension ( $1 \mathrm{mg} / \mathrm{mL}$ in methanol). The solvent was evaporated in air at room temperature. The tyrosinase enzyme was immobilized on the above GCE modified with SWCNTs (SWCNT-GCE) using a drop-and-dry technique followed by cross-linking. Next, $10 \mu \mathrm{L}$ of $0.01 \mathrm{M}$ PBS ( $\mathrm{pH} 7.0$ ) containing $50 \mu \mathrm{g} / \mu \mathrm{L}$ of enzyme was added onto the SWCNT-GCE surface. After drying, the biosensor was placed in a saturated glutaraldehyde vapor atmosphere for 10 minutes followed by drying in air for 15 minutes at room temperature. ${ }^{13}$ The biosensor was rinsed with PBS to remove any unbound enzyme from the biosensor surface. 


\section{Pharmacopoeia method}

The spectrophotometric method established in the Romanian Pharmacopoeia was used to compare the results obtained with the biosensor. According to this method, epinephrine in $0.01 \mathrm{M}$ hydrochloric acid solution showed maximum absorption at $279 \mathrm{~nm}$. For one real sample (articaine/adrenaline) analyzed, strong interference from articaine was demonstrated at this wavelength. The presence of this interfering agent did not affect amperometric analyses using the biosensor.

\section{Results and discussion Cyclic voltammetry studies}

The response of the biosensor when immersed in aqueous epinephrine solution was registered in the range from $-0.5 \mathrm{~V}$ to $+0.5 \mathrm{~V}$ at a scan rate of $0.050 \mathrm{~V}$ per second. Preliminary cyclic voltammetric experiments using GCE showed a reduction peak with a maximum current located at $-0.07 \mathrm{~V}$. This potential was selected, based on the preliminary experiments, and was later confirmed as the optimal potential in amperometric experiments. These experiments were carried out in PBS 0.01 M (pH 7.0), which was selected based on previous results. ${ }^{13}$

Figure 1 shows the cyclic voltammogram for the biosensor using $10^{-5} \mathrm{M}$ epinephrine in PBS (0.01 M, pH 7.0). The cyclic voltammogram for the tyrosinase/SWCNT-GCE biosensor in $10^{-5} \mathrm{M}$ epinephrine showed a peak at $-0.07 \mathrm{~V}$ (cathodic peak associated with reduction of the enzymatically formed epinephrine-quinone to epinephrine) and at $+0.12 \mathrm{~V}$ (anodic peak associated with electrochemical oxidation of epinephrine).


Figure I Cyclic voltammogram of biosensor immersed in $10^{-5} \mathrm{M}$ solution of epinephrine (supporting electrolyte phosphate-buffered saline, $\mathrm{pH}$ 7.0). Scan rate $50 \mathrm{mV}$ per second.
Tyrosinase catalyzes the oxidation of epinephrine to epinephrine-quinone, as shown in Figure 2. The o-quinone derivative that is generated can be reduced electrochemically at low potential without any electron mediator (Figure 3 ).

Therefore, epinephrine can be detected by electrochemical reduction of epinephrine-quinone. The presence of a reduction peak indicates that the immobilization process retains the biological activity of tyrosinase in SWCNTs with a modified surface. The value of the potential applied to monitor reduction of the species at the electrode surface was $-0.07 \mathrm{~V}$, in order to minimize the risk of possible electrochemical interference. ${ }^{22}$

\section{Influence of scan rate on biosensor response}

A kinetics study was performed by registering the cyclic voltammograms of the biosensor at different scan rates from 0.05 to $1.00 \mathrm{~V}$ per second (Figure 4, not all cyclic voltammograms are shown). The peak cathodic current was proportional to the sweep rates, pointing to a limited charge transfer process due to the catalytic activity of the enzyme deposited on the surface of the electrode. From the slope of $I_{p c}$ versus $v$ graph using the Laviron equation:

$$
\mathrm{I}_{\mathrm{pc}}=\mathrm{n}^{2} \mathrm{~F}^{2} \vee \mathrm{A} \Gamma / 4 \mathrm{R} T
$$

where $\mathrm{I}_{\mathrm{pc}}$ is the cathodic peak current (in amperes), $\mathrm{n}$ is the number of electrons involved in the redox process, $\mathrm{F}$ is the Faraday constant $(96,485.3365 \mathrm{C} / \mathrm{mol}), v$ is the potential scan rate (V per second), $\mathrm{A}$ is the electrode area $\left(\mathrm{cm}^{2}\right), \Gamma$ is the surface coverage of the redox species $\left(\mathrm{mol} / \mathrm{cm}^{2}\right), \mathrm{R}$ is the ideal gas constant (8.3144621 J/ K×mol), and T is the temperature (K), the total surface coverage could be calculated. ${ }^{23}$

The total surface coverage value was calculated to be $2.34 \times 10^{-10} \mathrm{~mol} / \mathrm{cm}^{2}$, a value which is in agreement with the literature. ${ }^{24}$ Therefore, the biocatalytic activity of the enzyme is preserved well when it is immobilized in a nanostructured carbonaceous environment.

The intensity of the anodic peak related to electrochemical oxidation of epinephrine increases linearly with the square root of the sweep rate, indicating a diffusion-
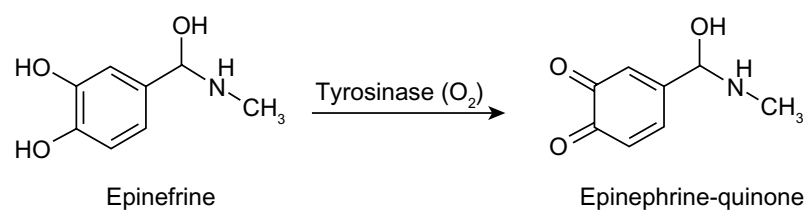

Figure 2 Enzymatic oxidation of epinephrine by tyrosinase. 
<smiles>CNC(O)c1ccc(O)c(O)c1</smiles>

Figure 3 Electrochemical reduction of o-epinephrine-quinone.

controlled process according to the Randles-Sevcik equation: ${ }^{23}$

$$
\mathrm{I}_{\mathrm{pa}}=2.687 \times 10^{5} \mathrm{n}^{3 / 2} \mathrm{v}^{1 / 2} \mathrm{D}^{1 / 2} \mathrm{AC}
$$

where $\mathrm{I}_{\mathrm{pa}}$ is the anodic peak current (amperes), $\mathrm{n}$ is the number of electrons involved in the redox process, $v$ is the potential scan rate (V per second), D is the diffusion coefficient $\left(\mathrm{cm}^{2}\right.$ per second), $\mathrm{A}$ is the electrode surface area $\left(\mathrm{cm}^{2}\right)$, and $\mathrm{C}$ is the concentration $(\mathrm{mM})$. From the slope of $\mathrm{I}_{\mathrm{pa}}$ versus $\mathrm{v}^{1 / 2}$ plot, the diffusion coefficient $\mathrm{D}$ was calculated. The calculated diffusion coefficient $\mathrm{D}$ was $7.87 \times 10^{-6} \mathrm{~cm}^{2}$ per second. This value is lower than that obtained in the case of modified gold electrodes. ${ }^{25}$ From the above results, it could be concluded that tyrosinase/SWCNT-GCE has a fast diffusion coefficient, indicating that electrochemical processes are occurring rapidly in the case of this biosensor.

\section{Influence of epinephrine concentration on biosensor response}

The effect of epinephrine concentration on the response of the biosensor was studied by cyclic voltammetry, immersing the electrode in solutions with different concentrations.

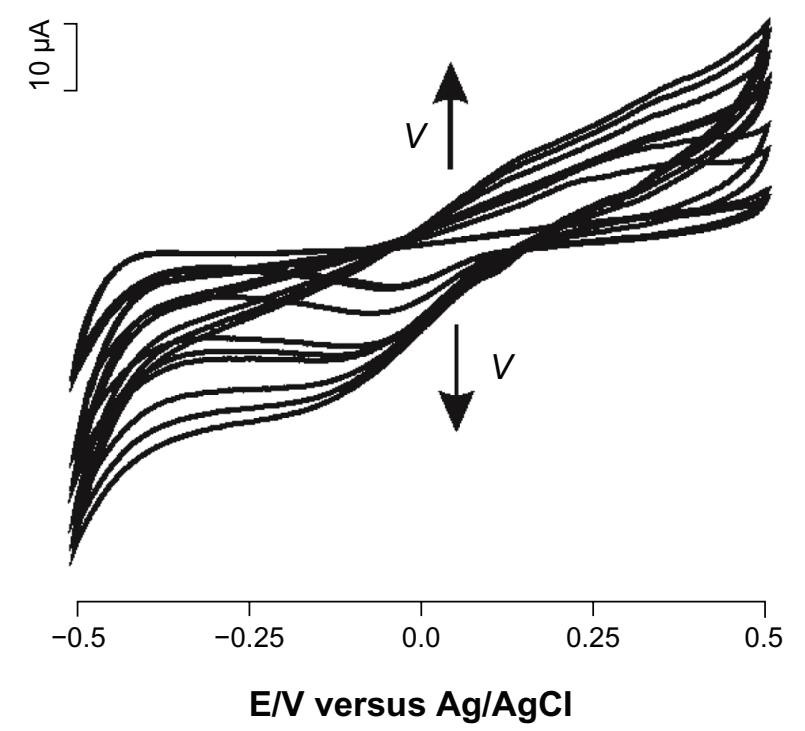

Figure 4 Cyclic voltammograms of biosensor immersed in $10^{-5} \mathrm{M}$ solution of epinephrine (supporting electrolyte phosphate-buffered saline, $\mathrm{pH} 7.0$ ) registered at different scan rates, from 0.05 to $1.00 \mathrm{~V}$ per second.
As observed in Figure 5, the intensity of the peaks increased with epinephrine concentration. Chronoamperometry was extensively used in the field of biosensors, even though the electrochemical signals obtained by cyclic voltammetry were highly reproducible. ${ }^{22,24}$ Therefore, chronoamperometry was used to record the calibration curves.

\section{Amperometric response of biosensor}

Figure 6 shows the amperometric response for the tyrosinase/ SWCNT-GCE biosensor at $-0.07 \mathrm{~V}$ after addition of successive aliquots $(20 \mu \mathrm{M})$ of epinephrine to $0.01 \mathrm{M}$ PBS (pH 7.0) under constant stirring. Reduction currents proportional to the concentration of epinephrine were observed, which resulted from the electrochemical reduction of epinephrinequinone formed enzymatically on the biosensor surface. The tyrosinase/SWCNT-GCE biosensor achieves 95\% of steady-state current in less than 5 seconds. This response rate is much faster than the 50 seconds reported for the silica sol-gel matrix. ${ }^{26}$ This fast response is attributed to rapid electron transfer between the enzymatically produced epinephrine-quinone and the electrode.

\section{Analytical performances of biosensor}

Figure 7 shows the relationship between the cathodic current of the biosensor and the epinephrine concentration in PBS ( $\mathrm{pH} 7.0$ ) at $-0.07 \mathrm{~V}$ for the tyrosinase/SWCNT-GCE biosensor under continuous stirring (calibration curve).

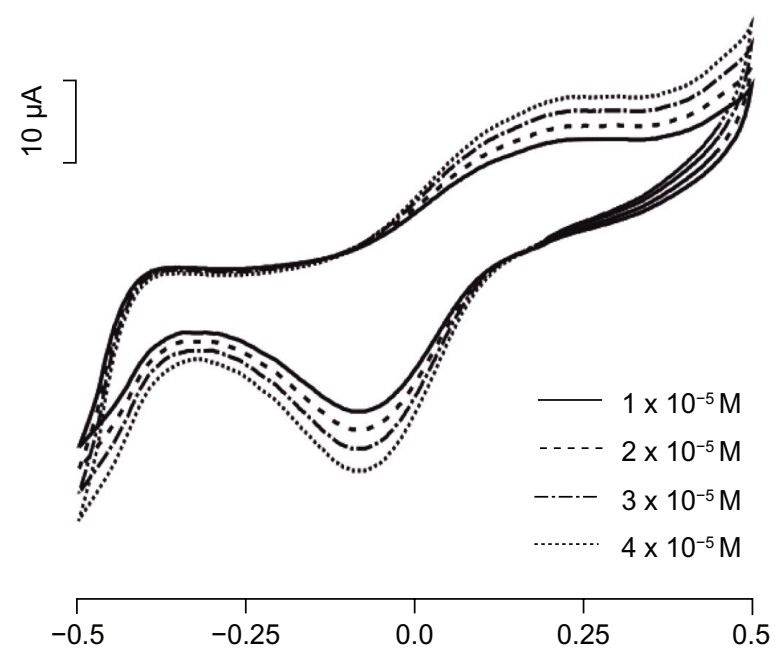

$\mathrm{E} / \mathrm{V}$ versus $\mathrm{Ag} / \mathrm{AgCl}$

Figure 5 Cyclic voltammograms of biosensor immersed in epinephrine solutions of different concentrations $\left(1 \times 10^{-5} \mathrm{M}, 2 \times 10^{-5} \mathrm{M}, 3 \times 10^{-5} \mathrm{M}\right.$, and $\left.4 \times 10^{-5} \mathrm{M}\right)$. 


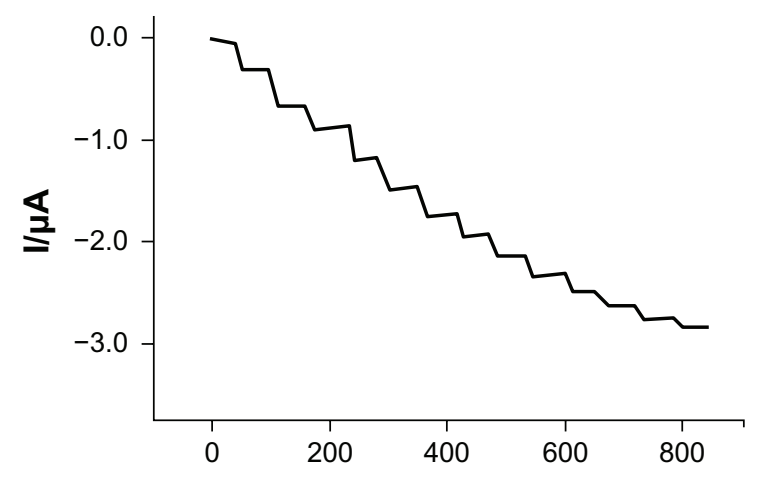

Time/s

Figure 6 Amperometric response of tyrosinase-based biosensor to epinephrine in $0.1 \mathrm{M}$ phosphate-buffered saline solution $(\mathrm{pH} \mathrm{7.0)}$ under constant stirring, with levels increasing in $20 \mu \mathrm{M}$ increments. Applied potential $-0.07 \mathrm{~V}$.

The response current of the tyrosinase/SWCNT-GCE biosensor is linearly related to the epinephrine concentration in the range of $10-110 \mu \mathrm{M}$, indicating that the catalytic enzymatic reaction of tyrosinase is a first-order reaction. After that, with further increases in epinephrine concentration, the current increases slowly, and the enzymatic reaction shows a transition from a first-order reaction to a zero-order reaction. The detection limit was calculated according to the $3 \mathrm{~s}_{\mathrm{b}} / \mathrm{m}$ criterion, where $m$ is the slope of the calibration graph and $s_{b}$ is the relative standard deviation $(n=5)$ of the amperometric signals at the lowest concentration of the calibration plot. The detection limit (LOD) was calculated to be $2.54 \mu \mathrm{M}$ and the correlation coefficient was 0.977 . The LOD value obtained is between the one reported by Tembe et al $\left(1 \times 10^{-5} \mathrm{M}\right)^{27}$ and that obtained by Mataveli et al $\left(8.0 \times 10^{-7} \mathrm{M}\right) .^{28}$ Thus, the biosensor is able to meet the requirements for practical application.
From the calibration data, the Hill coefficient (h) was calculated by representing $\log \left[\mathrm{I} /\left(\mathrm{I}_{\max }-\mathrm{I}\right)\right]$ versus $\log [\mathrm{S}]$ (logarithm of the substrate concentration). A Hill coefficient of $1.07 \pm 0.03$ was calculated for the reduction process of epinephrine-quinone formed from the enzymatic reaction on the electrode surface $\left(R^{2}=0.986\right)$. The value obtained for the $\mathrm{h}$ parameter was close to unity. This establishes that the kinetics of the enzymatic reaction fitted a MichaelisMenten type of kinetics. The value, slightly higher than 1 , shows a positive cooperative effect between the occupied active sites.

The apparent Michaelis-Menten constant $\left(\mathrm{K}_{\mathrm{M}}\right)$ of immobilized tyrosinase was calculated using the Lineweaver-Burk equation: ${ }^{23}$

$$
1 / \mathrm{I}=1 / \mathrm{I}_{\max }+\mathrm{K}_{\mathrm{M}} /\left(\mathrm{I}_{\max }[\mathrm{S}]\right)
$$

where I is the cathodic current, $\mathrm{I}_{\max }$ is the steady-state current, $\mathrm{K}_{\mathrm{M}}$ is the apparent Michaelis-Menten constant, and [S] is the concentration of substrate (epinephrine). The maximum current response and apparent Michaelis-Menten constant were calculated from the intercept and slope, respectively.

The values obtained for the biosensor detecting epinephrine were $\mathrm{I}_{\max }=2.22 \mu \mathrm{A}$ and $\mathrm{K}_{\mathrm{M}}=60.5 \mu \mathrm{M}$. The small value of the Michaelis-Menten constant indicates a strong affinity between tyrosinase and the substrate. In contrast, a higher $\mathrm{I}_{\max }$ indicates higher sensitivity of the biosensor. ${ }^{23}$

The values obtained have demonstrated that Ty/SWCNT nanocomposite film makes up a proper environment for enzyme immobilization. It preserves the enzyme's biocatalytic properties even in the case in which the immobilized

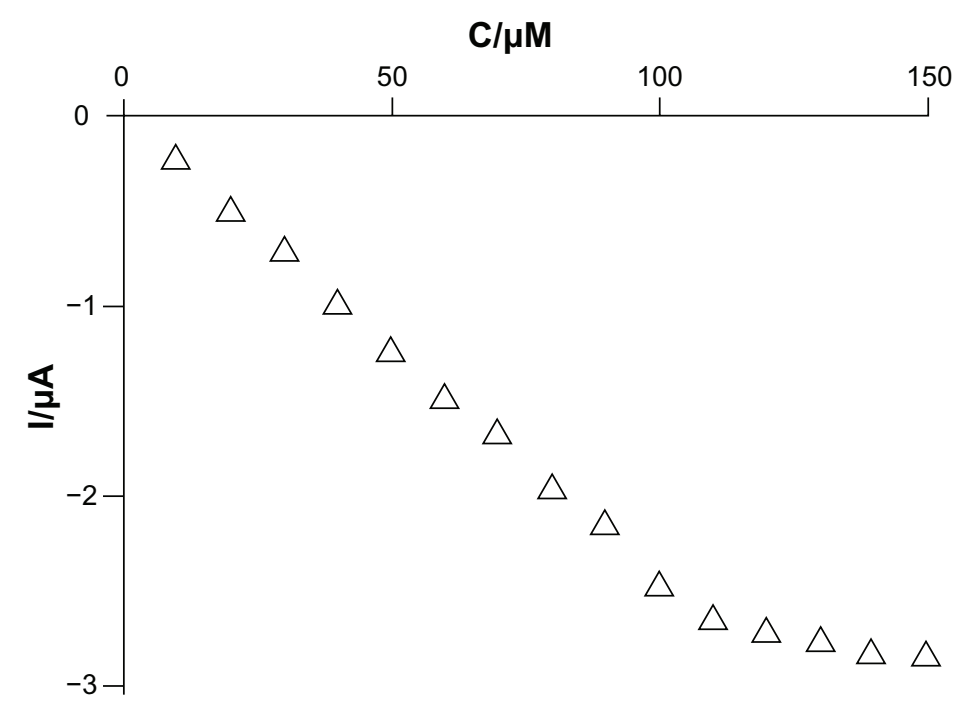

Figure 7 Calibration curve for the reduction current and concentration of epinephrine in phosphate-buffered saline ( $\mathrm{pH} 7.0)$. Applied potential $-0.07 \mathrm{~V}$. 
enzyme is one molecule whose movement in space has been completely limited or restricted to a small region. The interaction between tyrosinase and the SWCNTs involves physical adsorption of the enzyme by hydrophobic and electrostatic interaction. ${ }^{20}$

\section{Interference studies}

The influence of various interfering agents on determination of $50 \mu \mathrm{M}$ epinephrine was investigated. The result, expressed as the tolerance limit, was taken as the maximum concentration of the foreign substance which caused a relative error of approximately $\pm 5 \%$ in determination of the analyte. The concentration of interfering substances was $0.01 \mathrm{M}$ for $\mathrm{Na}^{+}$, $\mathrm{S}_{2} \mathrm{O}_{5}{ }^{2-}$, and $\mathrm{Cl}^{-}$; and $0.001 \mathrm{M}$ for urea, tartaric acid, and hydrochloric acid. The tolerated ratio of interfering substances to $50 \mu \mathrm{M}$ epinephrine was 2,200 for $\mathrm{Na}^{+}, \mathrm{S}_{2} \mathrm{O}_{5}{ }^{2-}$, and $\mathrm{Cl}^{-}$; and 750 for urea, and 240 for tartaric acid and hydrochloric acid, respectively. Glucose and glycine $0.001 \mathrm{M}$ do not have any influence in the biosensor response when detecting $50 \mu \mathrm{M}$ epinephrine. An absence of significant modification in the peak current recorded in the presence of the interfering species was demonstrated. Therefore, tyrosinase/SWCNT-GCE can be considered to be a good biosensor for recognition of epinephrine.

\section{Biosensor repeatability and stability}

To investigate the repeatability of the biosensor, amperometric measurements were performed in a $10^{-5} \mathrm{M}$ epinephrine solution using the same biosensor. The relative standard deviation of the measurements was $3.4 \%$. Between replicate measurements, the biosensor was cleaned by rinsing with $0.01 \mathrm{M}$ PBS at $\mathrm{pH}$ 7.0. Therefore, the biosensor is expected to be able to be used repeatedly.

The stability of the biosensor was studied by monitoring the amperometric response to $10^{-5} \mathrm{M}$ epinephrine solution at regular intervals (24 hours) for a period of one month. The biosensor was stored in a refrigerator at $4^{\circ} \mathrm{C}$ in $0.01 \mathrm{MPBS}$ at $\mathrm{pH}$ 7.0. The results reveal that the biosensor retained $87 \%$ of its current response after one month of storage.

\section{Application of the biosensor to detect epinephrine in pharmaceutical formulae}

The ultraviolet spectrophotometric method indicated in the $\mathrm{X}$ Romanian Pharmacopoeia ${ }^{29}$ recommends measurement of epinephrine at $279 \mathrm{~nm}$ in the presence of $0.01 \mathrm{M} \mathrm{HCl}$. A calibration curve was constructed using pure epinephrine. The pharmaceutical products were diluted in the same solvent, and absorbance at $279 \mathrm{~nm}$ was registered. From the calibration curve, the concentration of epinephrine was calculated while taking into account the dilution factor.

In the case of the biosensor, the addition method was used, whereby $50 \mu \mathrm{M}$ of epinephrine was added to the pharmaceutical solution. The biosensor was immersed in PBS 0.01 $\mathrm{M}$ at $\mathrm{pH} 7.0, \mathrm{a}-0.07 \mathrm{~V}$ potential was applied, and the solution was maintained under constant stirring. After stabilization, measured sample volumes were added and the cathodic currents were measured. Using the calibration curve, dilution factor, and quantity of epinephrine added, epinephrine concentrations in the pharmaceutical products were calculated. Table 1 shows the results obtained for analyses of pharmaceutical formulations using the official ultraviolet spectrophotometric procedure and the biosensor $(-0.07 \mathrm{~V}$ versus $\mathrm{Ag} / \mathrm{AgCl})$.

Following the Romanian Pharmacopoeia method, the values obtained were slightly higher than the value indicated on the labeling of the pharmaceutical product. This could be related to interference from other compounds present in the pharmaceutical product. However, in the case of the articaine/adrenaline product, a very significant difference was observed. The value obtained was due to interference from articaine, which shows maximum absorption at $272 \mathrm{~nm}$ in PBS (pH 6.8). ${ }^{30}$

The results obtained by amperometry using the biosensor were in very good agreement with the values registered on the labels of all the pharmaceutical products tested. Articaine has not been detected in the case of interfering compounds of the biosensor. This result is related to the specificity of tyrosinase for the phenolic groups in catecholamines. However, in two cases, a good relationship was found between the results obtained by each method. Consequently, the biosensor proposed in the present study can be successfully used in analysis of real samples.

Table I Determination of epinephrine in formulation by ultraviolet spectrophotometry and biosensor

\begin{tabular}{llll}
\hline Sample & $\begin{array}{l}\text { Label value } \\
(\mathbf{m g} / \mathbf{m L})\end{array}$ & $\begin{array}{l}\text { Pharmacopoeia } \\
\text { method }(\mathbf{m g} / \mathbf{m L})\end{array}$ & $\begin{array}{l}\text { Biosensor } \\
(\mathbf{m g} / \mathbf{m L})\end{array}$ \\
\hline $\begin{array}{l}\text { Anapen }{ }^{\circledR} \text { (Owen } \\
\text { Mumford Ltd, }\end{array}$ & $\mathrm{I}$ & 1.010 & 0.993 \\
$\begin{array}{l}\text { Woodstock, UK) } \\
\text { Adrenaline I mg }\end{array}$ & $\mathrm{I}$ & $\mathrm{I} .04 \mathrm{I}$ & \\
$\begin{array}{l}\text { (Terapia SA, Cluj- } \\
\text { Napoca, Romania) }\end{array}$ & & 0.986 \\
$\begin{array}{l}\text { Articaine/adrenaline } \\
\text { (Sanofi-Aventis }\end{array}$ & 0.010 & 36.226 & 0.012 \\
$\begin{array}{l}\text { Deutschland GmbH, } \\
\text { Berlin, Germany) }\end{array}$ & & & \\
\hline
\end{tabular}

Note: Relative standard deviation for Romanian Pharmacopoeia method was 2.2\%; relative standard deviation for biosensor was $3.5 \%$. 


\section{Conclusion}

This study demonstrates the possibility of developing a SWCNT-GCE-based biosensor for monitoring epinephrine in aqueous solution. It confirms that the SWCNT-GCE can be used as an appropriate matrix for immobilization of tyrosinase. The biosensor shows a rapid response, good sensitivity, and high stability for amperometric detection of epinephrine. The efficiency of the biosensor for epinephrine determination in pharmaceutical formulae has been demonstrated. The concentration results show good agreement with those obtained using the Romanian Pharmacopoeia method. Therefore, the proposed biosensor is a potential method for epinephrine quantification in pharmaceutical products and biological samples.

\section{Acknowledgment}

This work was supported by a grant from the Romanian National Authority for Scientific Research, CNCSUEFISCDI, project number PN-II-ID-PCE-2011-3-0255.

\section{Disclosure}

The authors report no conflicts of interest in this work.

\section{References}

1. Stolk JM, U'Prichard DC, Fuxe K, editors. Epinephrine in the Central Nervous System. Cary, NC: Oxford University Press; 1988.

2. Devlin TM, editor. Textbook of Biochemistry: With Clinical Correlations. 5th ed. New York, NY: Wiley; 2002.

3. Sheikh A, Shehata YA, Brown SG, Simons FE. Adrenaline for the treatment of anaphylaxis: Cochrane systematic review. Allergy. 2009;64:204-212.

4. Berridge CW, Waterhouse BD. The locus coeruleus-noradrenergic system: modulation of behavioral state and state-dependent cognitive processes. Brain Res Rev. 2003;42:33-84.

5. Sanghavi BJ, Mobin SM, Mathur P, Lahiri GK, Srivastava AK. Biomimetic sensor for certain catecholamines employing copper(II) complex and silver nanoparticle modified glassy carbon paste electrode. Biosens Bioelectron. 2013;39:124-132.

6. Kim SH, Lee JW, Yeo IH. Spectroelectrochemical and electrochemical behavior of epinephrine at a gold electrode. Electrochim Acta. 2000;45: 2889-2895.

7. Guo Y, Yang J, Wu X, Du A. A sensitive fluorimetric method for the determination of epinephrine. J Fluoresc. 2005;15:131-136.

8. Zhang G, Zhang Y, Ji C, et al. Ultra sensitive measurement of endogenous epinephrine and norepinephrine in human plasma by semiautomated SPE-LC-MS/MS. J Chromatogr B Analyt Technol Biomed Life Sci. 2012;895-896:186-190.

9. Zhang X, Xu S, Lim JM, Lee YI. Molecularly imprinted solid phase microextraction fiber for trace analysis of catecholamines in urine and serum samples by capillary electrophoresis. Talanta. 2012;99: 270-276.

10. Mo Z, Long X, Zhang M. Piezoelectric detection of ion pairs between sulphonate and catecholamines for flow injection analysis of pharmaceutical preparations. Talanta. 1999;48:643-648.
11. Tombelli S, Mascini M. Aptamers biosensors for pharmaceutical compounds. Comb Chem High Throughput Screen. 2010;13: 641-649.

12. Ates M, Sarac AS. Conducting polymer coated carbon surfaces and biosensor applications. Progress in Organic Coatings. 2009;66: $337-358$.

13. Apetrei IM, Rodriguez-Mendez ML, Apetrei C, de Saja JA. Enzyme sensor based on carbon nanotubes/cobalt(II) phthalocyanine and tyrosinase used in pharmaceutical analysis. Sens Actuators B Chem. 2013;177:138-144.

14. Apetrei C, Rodriguez-Mendez ML, de Saja JA. Amperometric tyrosinase based biosensor using an electropolymerized phosphate-doped polypyrrole film as an immobilization support: application for detection of phenolic compounds. Electrochim Acta. 2011;56:8919-8925.

15. Liu Z, Deng J, Li D. A new tyrosinase biosensor based on tailoring the porosity of $\mathrm{Al}_{2} \mathrm{O}_{3}$ sol-gel to co-immobilize tyrosinase and the mediator. Anal Chim Acta. 2000;407:87-96.

16. Apetrei C, Alessio P, Constantino CJL, et al. Biomimetic biosensor based on lipidic layers containing tyrosinase and lutetium bisphthalocyanine for the detection of antioxidants. Biosens Bioelectron. 2011;26: 2513-2519.

17. Cabaj J, Soloducho J, Nowakowska-Oleksy A. A Langmuir-Blodgett film based biosensor for estimation of phenol derivatives. Sens Actuators B Chem. 2010;143:508-515.

18. IostRM, MadurroJM, Brito-MadurroAG, Nantes IL, CaseliL, CrespilhoFN. Strategies of nano-manipulation for application in electrochemical biosensors. Int J Electrochem Sci. 2011;6:2965-2997.

19. Saifuddin N, Raziah AZ, Junizah AR. Carbon nanotubes: a review on structure and their interaction with proteins. J Chem. 2013;2013:ID 676815.

20. Feng W, Ji P. Enzymes immobilized on carbon nanotubes. Biotechnol Adv. 2011;29:889-895.

21. Tang N, Zheng JB, Sheng QL, Zhang HF, Liu RX. A novel $\mathrm{H}_{2} \mathrm{O}_{2}$ sensor based on the enzymatically induced deposition of polyaniline at a horseradish peroxide/aligned single-wall carbon nanotubes modified Au electrode. Analyst. 2011;136:781-786.

22. Mello LD, Taboada Sotomayor MDP, Kubota LT. HRP-based amperometric biosensor for the polyphenols determination in vegetables extract. Sens Actuators B Chem. 2003;96:636-645.

23. Bard AJ, Faulkner LR. Electrochemical Methods. New York, NY: John Wiley and Sons; 2001.

24. Apetrei IM, Bahrim G, Rodriguez-Mendez ML. Electrochemical study of polyphenols with amperometric tyrosinase based biosensors. Rom Biotechnol Lett. 2012;17:7684-7693.

25. Agboola BO, Ozoemena KI. Electrochemistry at cobalt(II) tetrasulfophthalocyanine-multi-walled carbon nanotubes modified glassy carbon electrode: a sensing platform for efficient suppression of ascorbic acid in the presence of epinephrine. Electroanalysis. 2008;15:1696-1707.

26. Li J, Chia LS, Goh NK, Tan SN. Silica sol-gel immobilised amperometric biosensor for the determination of phenolic compounds. Anal Chim Acta. 1998;362:203-211.

27. Tembe S, Kulkarni S, Karve M, D’Souza SF. Epinephrine biosensor using tyrosinase immobilized eggshell membrane. Sensors and Transducers Journal. 2009;107:111-118.

28. Mataveli LR, de Jesus Antunes N, Brigagão MR, de Magalhães CS, Wisniewski C, Luccas PO. Evaluation of a simple and low cost potentiometric biosensor for pharmaceutical and in vivo adrenaline determination. Biosens Bioelectron. 2010;26:798-802.

29. Romanian Pharmacopoeia. Editia a X-a. Bucharest, Romania: Ed Medicala; 1993.

30. Kulkarni AP, Khan SKA, Zaheer ZA, Dehghan MH. Spectroscopic estimation of articaine hydrochloride. J Pharm Res. 2011;4: 1596-1597. 
International Journal of Nanomedicine

Dovepress

\section{Publish your work in this journal}

The International Journal of Nanomedicine is an international, peerreviewed journal focusing on the application of nanotechnology in diagnostics, therapeutics, and drug delivery systems throughout the biomedical field. This journal is indexed on PubMed Central, MedLine, CAS, SciSearch $\AA$, Current Contents ${ }^{\circledR} /$ Clinical Medicine,

Journal Citation Reports/Science Edition, EMBase, Scopus and the Elsevier Bibliographic databases. The manuscript management system is completely online and includes a very quick and fair peer-review system, which is all easy to use. Visit http://www.dovepress.com/ testimonials.php to read real quotes from published authors.

Submit your manuscript here: http://www.dovepress.com/international-journal-of-nanomedicine-journal 